
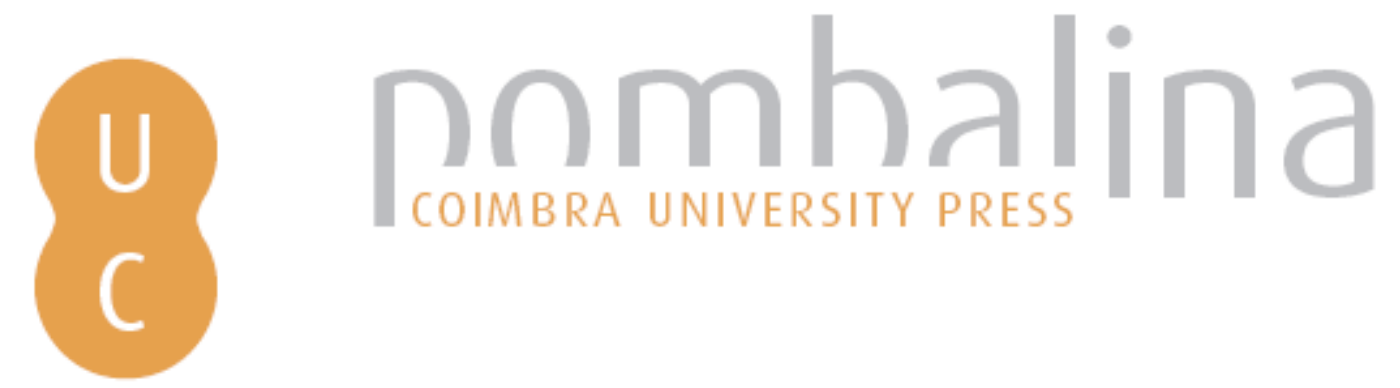

\title{
A emigração na ilha Graciosa: estudo de caso dos emigrantes graciosenses nos estados da Califórnia e Massachusetts (EUA)
}

Autor(es): $\quad$ Espínola, Paulo

Publicado por: Imprensa da Universidade de Coimbra

URL

persistente: URI:http://hdl.handle.net/10316.2/31174

DOI: $\quad$ DOI:http://dx.doi.org/10.14195/978-989-26-0244-8_78

Accessed : $\quad$ 26-Apr-2023 08:29:01

A navegação consulta e descarregamento dos títulos inseridos nas Bibliotecas Digitais UC Digitalis, UC Pombalina e UC Impactum, pressupõem a aceitação plena e sem reservas dos Termos e Condições de Uso destas Bibliotecas Digitais, disponíveis em https://digitalis.uc.pt/pt-pt/termos.

Conforme exposto nos referidos Termos e Condições de Uso, o descarregamento de títulos de acesso restrito requer uma licença válida de autorização devendo o utilizador aceder ao(s) documento(s) a partir de um endereço de IP da instituição detentora da supramencionada licença.

Ao utilizador é apenas permitido o descarregamento para uso pessoal, pelo que o emprego do(s) título(s) descarregado(s) para outro fim, designadamente comercial, carece de autorização do respetivo autor ou editor da obra.

Na medida em que todas as obras da UC Digitalis se encontram protegidas pelo Código do Direito de Autor e Direitos Conexos e demais legislação aplicável, toda a cópia, parcial ou total, deste documento, nos casos em que é legalmente admitida, deverá conter ou fazer-se acompanhar por este aviso.

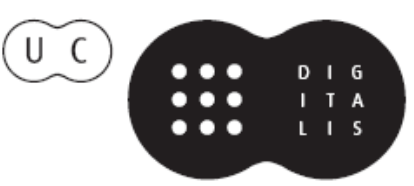




\section{TRUNFOS DE UMA}

\section{EOGRAFIA ACIVA}

\section{DESENVOLVIMENTO LOCAL,}

AMBIENTE,

ORDENAMENTO

E TECNOLOGIA

Norberto Santos

Lúcio Cunha

COORDENAÇÃO 
Paulo Espínola

\section{A EMIGRAÇÃO NA ILHA GRACIOSA. ESTUDO DE CASO DOS EMIGRANTES GRACIOSENSES NOS ESTADOS DA CALIFÓRNIA E MASSACHUSETTS (EUA)}

\section{NOTA INTRODUTÓRIA}

A Graciosa é uma das 9 ilhas dos Açores, situando-se a $28^{\circ} 05^{`}$ a Oeste de Greenwich e a $39^{\circ} 05^{\prime}$ a Norte do Equador, sendo a ilha mais setentrional do grupo central deste arquipélago. É a segunda ilha com menor superfície dos Açores, com cerca de $62 \mathrm{~km}^{2}$ (somente à frente da ilha do Corvo). Porém, em termos demográficos ocupava no ano 2001 a antepenúltima posição com 4780 habitantes (à frente das ilhas do grupo ocidental - Flores e Corvo). A Graciosa apresenta-se com um único concelho - Santa Cruz da Graciosa - constituído por quatro freguesias: Guadalupe, Luz, São Mateus e Santa Cruz.

O grande motivo que nos levou a produzir este artigo foi o facto de qualquer população desta ilha não ser muito conhecida a nível nacional. Logo, esta é uma forma de a tentar divulgar, nomeadamente a população que é emigrante. Para além disso, é uma população muito pouco estudada, daí que esta investigação tenha raízes algo originais no que se refere ao estudo realizado no âmbito desta temática.

O principal método de investigação utilizado neste trabalho foi a aplicaçáo de um inquérito a 204 indivíduos que à data da sua realização (Verão do ano 2007) se constituíam como emigrantes graciosenses definitivos nos estados de Massachusetts ou da Califórnia (EUA). Efectuados os inquéritos, o tratamento dos dados foi realizado no programa Microsoft Office Excel 2007, no qual, através do relacionamento de variáveis, foi possível retirar conclusóes pertinentes.

O objectivo principal da aplicação dos inquéritos foi comparar as comunidades graciosenses dos dois estados, encontrando as suas diferenças e semelhanças. Contudo, também tentou-se averiguar as relaçóes que os emigrantes têm com a sua terra natal. Para além disso, tentaremos, dentro do possível, efectuar uma caracterizaçáo socioeconómica do tipo de emigrante graciosense e avaliar até que ponto a emigraçáo contribuiu para melhorar o bem-estar daqueles cidadãos.

$\mathrm{O}$ presente artigo encontra-se organizado em dois capítulos principais. O primeiro intitula-se "A interferência da emigração na demografia graciosense" e o segundo, que faz a análise dos resultados do inquérito efectuado, designa-se por "Estudo de caso sobre os emigrantes nos estados da Califórnia e Massachusetts (EUA). ” 


\section{A INTERFERÊNCIA DA EMIGRAÇÃO NA DEMOGRAFIA GRACIOSENSE}

Apresentando-se em 1864 com 8718 habitantes, a Graciosa baixou de forma progressiva a sua população até atingir 7477 habitantes em 1920. A partir deste ano e até $1950 \mathrm{a}$ ilha viu a sua população aumentar de forma muito acentuada (ano em que atinge o seu máximo demográfico - 9517 habitantes). Desde meados do século XX até à actualidade que a Graciosa registou contínuas perdas demográficas. Contudo, foi entre 1950 e 1981 que a redução demográfica foi muito mais significativa, na ordem dos $-43,5 \%$. Nos últimos 20 anos do século XX, a descida demográfica teve menos expressão, embora mantendo algum significado, cifrando-se nos $-11,1 \%$.

Figura 1 - Pirâmide etária da população da ilha Graciosa em 1981.

(Elaborado a partir do INE, 1983)

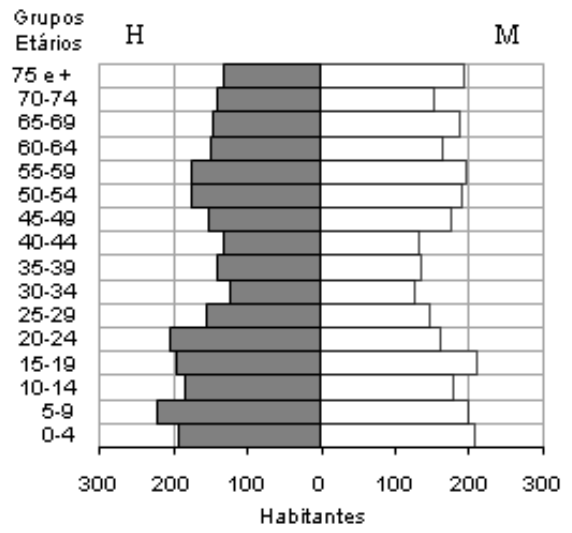

Numa análise mais pormenorizada, facilmente percebemos que a Graciosa, face à sua reduzida dimensão, situação de isolamento e baixo nível de vida dos seus habitantes, sempre se revelou uma ilha bastante repulsiva. A comprovar esta situaçáo está o facto de ao longo dos últimos 70 anos nunca ter registado um saldo migratório positivo. Deste modo, chegamos à conclusão que os ganhos demográficos estiveram relacionados com elevadas taxas de crescimento natural, enquanto as quebras populacionais revelaram saldos migratórios extremamente negativos. Esta relação apenas não se pode aplicar às duas últimas décadas do século XX, período em que o crescimento natural, cada vez mais negativo, assumiu-se como a variável mais preponderante na regressáo populacional. Assim, podemos concluir que recentemente o fenómeno emigratório perdeu importância directa no condicionamento da evolução demográfica da Graciosa. Contudo, o grande decréscimo populacional ocorrido entre 1950 e 1980 deveu-se em exclusivo à elevada corrente emigratória, que contrariou os elevados níveis de crescimento natural da época. Aliás, na estrutura etária da população da Graciosa de 1981 são evidentes os reflexos desta intensa corrente emigratória. Por conseguinte, e de uma forma geral, nota-se um significativo estreitamento das classes etárias correspondentes aos jovens adultos (Figura 1). Naturalmente que a saída de jovens adultos condicionou a base da pirâmide etária, uma vez que estes deixaram de ser potenciais procriadores na populaçáo graciosense. Deste modo, a taxa de natalidade sofreu uma descida 
significativa, bem como o grupo etário que está directamente implicado - os jovens. Ora, verificando-se a reduçáo dos jovens e do grupo dos adultos, os idosos foram aumentando gradualmente a sua proporção no total da população da ilha, ultrapassando o número de jovens no ano 2001. Com um envelhecimento demográfico cada vez mais pronunciado, naturalmente a taxa de mortalidade aumentou, o que tornou o saldo fisiológico ainda mais negativo. Desta forma, a população graciosense já não garante a substituição natural das suas geraçóes, o que se tem traduzido num declínio demográfico sucessivo. Assim, podemos dizer, com alguma segurança, que a condicionar todos estes indicadores demográficos esteve, em primeiro lugar, a variável emigraçáo. Logo, constatamos que a intensa emigraçáo registada na Graciosa nas primeiras três décadas da segunda metade do século XX provocaram profundas alteraçóes na demografia da ilha. Posto isto, interessa saber quais são os números envolvidos na corrente emigratória e em que áreas do mundo se fixaram preferencialmente esses graciosenses.

Apenas foi possível recolher o número de emigrantes por países de destino entre 1955 e 1988, período em que emigraram cerca de 4546 graciosenses. Destes, 1363 escolheram o Canadá como destino, enquanto 3000 optaram pelos EUA. Para além destes países, nenhum outro exerceu importante atracçáo sobre os habitantes graciosenses (Figura 2).

Figura 2 - A evolução da emigração da Graciosa por países de destino, no período 1955-1988.

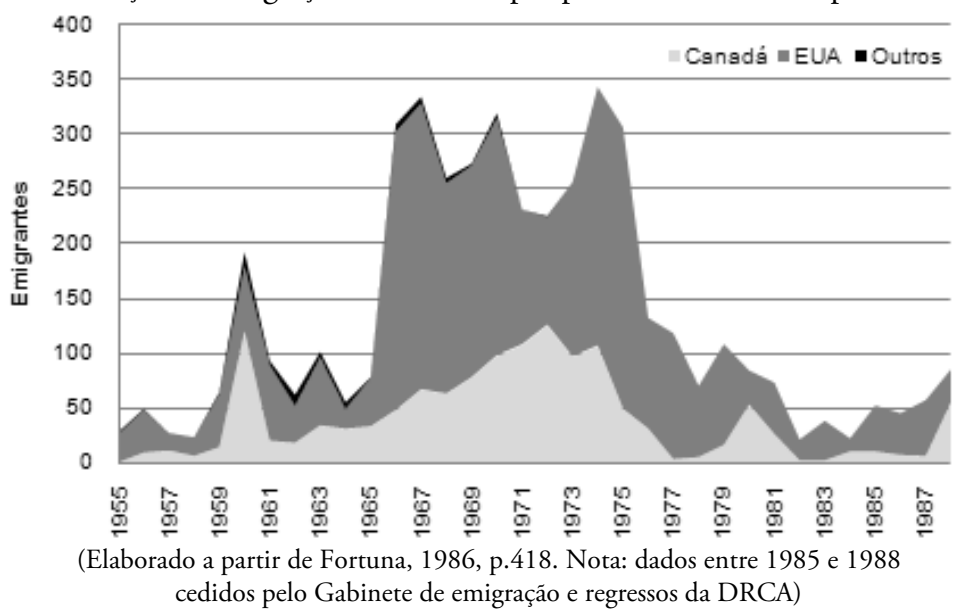

É entre 1960 e 1981 que corresponde a quase totalidade da emigração graciosense, podendo mesmo ser considerado o período "negro" da demografia da Graciosa, pois nesses 21 anos terão partido para o estrangeiro cerca de 4037 habitantes, o que náo deixa de ser um valor muito significativo para uma população que em 1960 não contava com mais de 8669 pessoas. Porém, num olhar ainda mais pormenorizado, são os dez anos que vão de 1966 a 1975 que constituíram o período de emigração mais intenso na ilha, época em que saíram em média 287 emigrantes por ano. De salientar que foi o ano de 1974 que atingiu o valor mais elevado de emigrantes -345 .

Em síntese, podemos dizer que o "emagrecimento" da população graciosense deveu-se no seu essencial à intensa corrente emigratória que ocorreu na segunda metade do século 
XX para a América do Norte, sendo indiscutível que foram os EUA que acolheram maior número de graciosenses. Daí que o estudo de caso apresentado neste trabalho tenha sido realizado nesse país, nos seus dois estados que receberam, indubitavelmente, o maior contingente desses emigrantes e sobre o qual o capítulo seguinte se vai debruçar.

\section{Estudo DE CASO SObRe os EMIGRANTES NOS ESTAdos dA CALIFÓRnia E MASSACHUSETTS (EUA)}

\subsection{Nota metodológica}

O desenvolvimento deste estudo de caso baseou-se num inquérito ${ }^{1}$ efectuado a 204 emigrantes graciosenses que se constituíam como residentes permanentes no Verão do ano 2007 em dois estados norte-americanos: 104 em Massachusetts e 100 na Califórnia. Houve duas ordens de razóes principais para termos seleccionado estes estados: em primeiro lugar, por serem os que reúnem o maior número de graciosenses residentes entre os 50 estados dos EUA. Em segundo lugar, porque são espaços muito distanciados entre si, o que poderia, à partida, perspectivar evoluçóes diferenciadas nas populaçôes emigrantes entre ambos, dado que já passaram cerca de 30 anos sobre o fecho do grande ciclo emigratório graciosense (Figura 3).

Figura 3 - Localização dos estados de Massachusetts e da Califórnia, nos EUA contínuos.

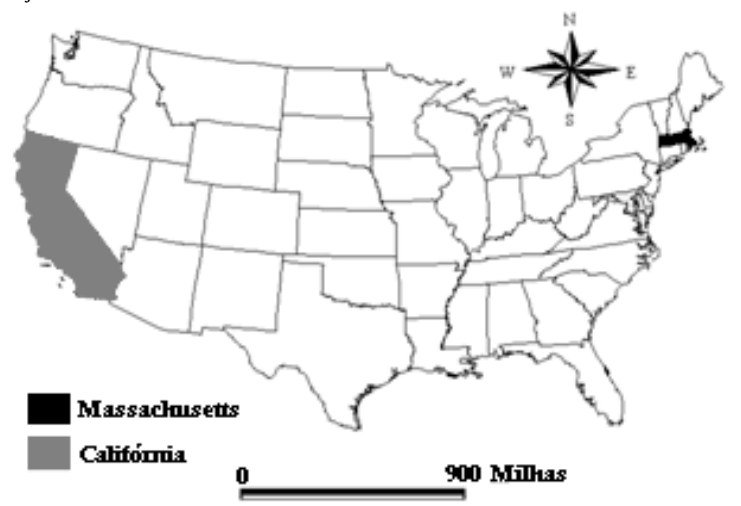

(Elaboração própria, 2007)

\subsection{O perfil do emigrante graciosense e a chegada ao novo país}

Concluímos sem surpresa, que os emigrantes à chegada ao novo país, independentemente do estado de residência, apresentaram sensivelmente o mesmo perfil: caracterizandose por ser uma população bastante jovem (idade média dos inquiridos no momento da chegada foi de 23,5 anos), com fraco nível de instrução (apenas 9,8\% da amostra possuía habilitaçóes superiores à antiga $4^{\text {a }}$ classe!) e apresentando somente experiência profissional ao

\footnotetext{
${ }^{1} \mathrm{O}$ modelo deste inquérito pode ser consultado em Espínola, 2008, pp. 241 - 243.
} 
nível de assalariados agrícolas, no caso dos homens, e de domésticas, no caso das mulheres (estas constituíam $85 \%$ da população inactiva da época). A emigração graciosense foi fundamentalmente familiar, motivada sobretudo por razóes económicas, numa corrente transoceânica em que quase não há registo de situaçóes de clandestinidade, dado que a grande maioria das emigraçóes concretizaram-se através de carta de chamada de familiares.

Em termos temporais, verificamos que a maioria dos inquiridos da amostra chegou aos EUA entre 1966 e 1976 - que coincide precisamente com o período de emigraçáo mais intenso na Graciosa. No entanto, e de um modo geral, podemos referir que a emigraçáo para Califórnia se efectuou há mais tempo. Assim, para os inquiridos que chegaram ao novo país até $1968^{2}, 73,3 \%$ optaram por estabelecer residência na Califórnia. Contudo, em relação aos inquiridos chegados aos EUA entre 1978 e 2005, 78,4 \% fixaram-se em Massachusetts.

Em termos espaciais, encontramos diferenças significativas entre ambas as comunidades emigrantes. Assim, em Massachusetts detectamos uma tendência para a concentração de graciosenses, enquanto na Califórnia os emigrantes se encontram mais dispersos no território. A comprovar esta ideia, está o facto de somente termos entrevistado graciosenses de Massachusetts com residência em quatro cidades, sendo que duas delas - Lowell e Peabody - centralizaram cerca de $98,1 \%$ do total de indagados nesse estado. No que se refere à Califórnia, apesar da grande concentração de inquiridos na cidade de São José (54\%), os restantes estão dispersos por mais 20 cidades, que na maioria das vezes localizam-se a distâncias muito significativas entre elas. A justificação principal para esta diferença entre os dois estados, ao nível do local de residência dos inquiridos, relaciona-se com o facto de termos tido grande facilidade em encontrar graciosenses nas duas principais cidades de Massachusetts consideradas, enquanto na Califórnia a dificuldade que sentimos a certa altura para atingir a meta que tínhamos estabelecido fez-nos percorrer enormes distâncias em busca de mais inquiridos. Esta situação levou-nos a concluir que existem muitos mais emigrantes em Massachusetts em comparação com a Califórnia. Além disso, como os graciosenses estão muito mais concentrados naquele estado, têm maior facilidade em estabelecer contactos entre eles, daí conviverem diariamente/semanalmente em festas, cafés, clubes recreativos ou mesmo com grande probabilidade de possuírem vizinhos graciosenses, sendo frequente ouvir-se falar entre os inquiridos da sua ilha, do facto de serem graciosenses e de terem saudades da Graciosa. Em relação ao estado californiano, devido à grande dificuldade em encontrar vizinhança graciosense, na maioria dos casos, os inquiridos inseriram-se em sociedades recreativas açorianas com grande participação de emigrantes de outras ilhas (como São Jorge e Terceira, as comunidades açorianas maioritárias naquele estado). É comum falarem entre eles que têm saudades das ilhas, que são dos Açores, que querem ir às ilhas! Encontramos nesta situação uma outra relação: a concentração de graciosenses permitiu manter o espírito insular de ilha, enquanto a dispersão emigrante graciosense facilitou o aprofundamento do espírito insular de arquipélago.

\subsection{A estrutura profissional da amostra}

Relativamente à estrutura profissional dos inquiridos à data da realização do inquérito, registamos que a taxa de actividade da nossa amostra foi de $67 \%$, todavia esta taxa foi maior em Massachusetts, dado que a Califórnia registou mais gente inactiva (Figura 4).

\footnotetext{
${ }^{2}$ Até 1976 a Califórnia ainda possuía a maioria dos inquiridos, com cerca de 58,2\% da totalidade.
} 
Esta discrepância está directamente relacionada com a diferença ao nível da idade média actual dos inquiridos entre os dois estados. Assim, enquanto em Massachusetts a idade média dos indagados foi de 53 anos, na Califórnia aumentou para os 61 anos, daí que existisse maior número de reformados neste último estado.

Figura 4 - Distribuição dos inquiridos activos pelos sectores de actividades económicas e dos inactivos pelos estados da Califórnia e de Massachusetts.

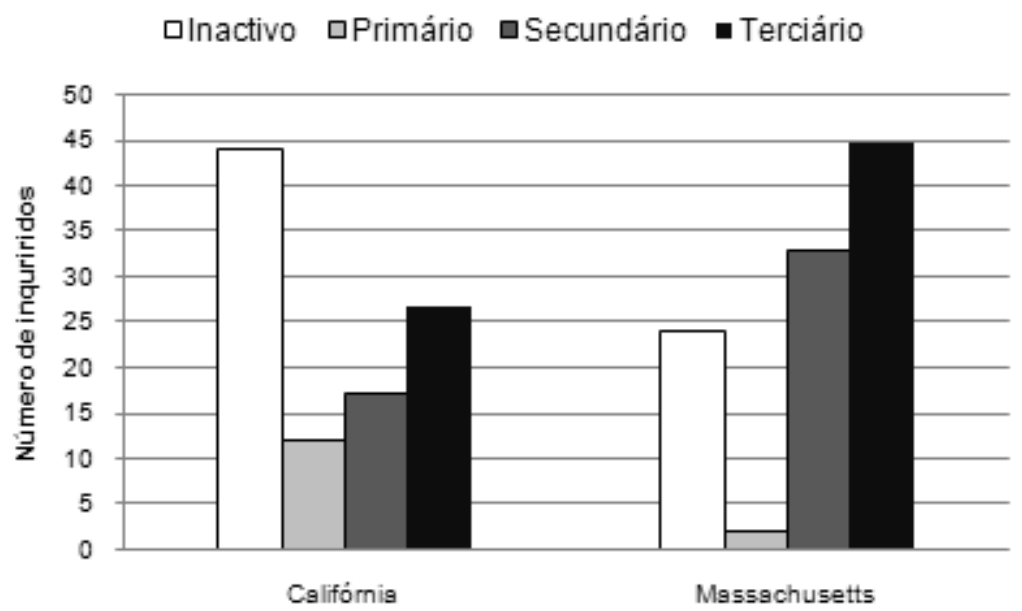

(Elaborado a partir dos inquéritos aos emigrantes graciosenses, Espínola, P. 2008)

Considerando os sectores de actividade económica que ocupam profissionalmente a população activa da nossa amostra, observamos que é o terciário que emprega actualmente mais máo-de-obra em ambos os estados, surgindo em segundo lugar o sector secundário, contudo, este sector destaca-se muito mais em Massachusetts em relação ao estado do Pacífico. Isto porque, na Califórnia não houve uma grande diferença entre este sector e o primário, 28,7\% e 21,4\% respectivamente. Enquanto em Massachusetts o secundário representava 41,4\% do total de inquiridos neste estado, sendo que o primário não foi além dos $2,5 \%$.

O motivo que faz com que a Califórnia possua um número considerável de inquiridos ligados à actividade agro-pecuária deve-se, em grande medida, ao facto de este estado possuir um clima de características mediterrâneas, possibilitando aos emigrantes trabalhar a terra como acontece em Portugal, cultivando as mesmas culturas, o que atraiu desde sempre grande número de emigrantes, uma vez que se trata da sua origem profissional. Contudo, não se pense que a grande maioria dos graciosenses está ligada a esta actividade na condição de assalariado agrícola, são muitos os exemplos de proprietários de grandes exploraçôes agrícolas. Por outro lado, no vale de Sáo Joaquim da Califórnia também é comum encontrar graciosenses que são donos de grandes exploraçoóes de gado. Aliás, esta característica dos inquiridos californianos - o facto de haver uma significativa percentagem de inquiridos que desempenham a função de patrão/empregador no sector primário estende-se de uma forma geral aos outros sectores de actividade económica, ao contrário do que acontece em Massachusetts, em que a esmagadora maioria da amostra surge na condição de empregado por conta de outrem. 


\subsubsection{O regresso temporário}

Foi com alguma estranheza que verificamos que $9,8 \%$ do total de inquiridos entrevistados nunca mais voltaram à Graciosa, após terem chegado ao país da emigração. Destes, $90 \%$ residem na Califórnia. Além disso, 61\% dos inquiridos deste estado não têm por hábito visitar a Graciosa, enquanto 75\% dos indagados de Massachusetts costumam visitar regularmente a sua terra natal. Embora existam diversas razóes que podem ser apontadas para justificar esta diferença entre ambos os estados, concluímos que a mais importante relaciona-se com o tipo de ligaçóes familiares que os inquiridos possuem na sua ilha de origem (Quadro 1).

Quadro 1 - Percentagem de inquiridos com familiares na Graciosa, segundo o grau de parentesco, por estado de residência.

\begin{tabular}{|l|c|c|c|}
\hline Grau de Parentesco & Califórnia & Massachusetts & Geral \\
\hline Avós & 0,0 & 6,7 & 3,4 \\
\hline Pais & 9,0 & 20,2 & 14,7 \\
\hline Irmáos & 2,3 & 41,3 & 32,4 \\
\hline Tios & 41,0 & 52,9 & 47,1 \\
\hline Primos & 79,0 & 89,4 & 84,3 \\
\hline Sobrinhos & 30,0 & 47,1 & 38,7 \\
\hline Netos & 2,0 & 3,8 & 2,9 \\
\hline
\end{tabular}

(Elaborado a partir dos inquéritos aos emigrantes graciosenses, Espínola, P. 2008)

De uma forma geral, constatamos que existe uma relação directa entre o tipo de ligaçóes familiares que os inquiridos possuem na sua terra natal e o número de vezes que a visitam. Ora, como de uma forma geral a emigração para a Califórnia ocorreu há mais tempo, na generalidade estes inquiridos possuem menos relaçóes familiares de proximidade na Graciosa, daí serem os que regressam menos vezes à sua terra natal.

\subsubsection{O regresso definitivo}

Questionados sobre o possível regresso definitivo à ilha Graciosa, apenas 15,2\% do total da amostra responderam de forma afirmativa. Existe também neste aspecto uma diferença algo expressiva entre os dois estados, pois, enquanto $24,0 \%$ dos inquiridos de Massachusetts pretendem residir novamente de modo permanente na Graciosa, na Califórnia somente $6,0 \%$ têm esse objectivo.

Dos indagados que não desejam um regresso definitivo à terra natal, aproximadamente $2 / 3$ apontaram as afinidades familiares que possuem no actual país de residência para não voltarem a residir na sua ilha de origem. De facto, são os inquiridos que apresentam descendentes nos EUA que mais recusam a ideia de voltar a viver na Graciosa, pois estão conscientes que a fixação definitiva na terra onde nasceram implicaria um afastamento dos seus filhos e netos, o que originaria uma divisão familiar. Além disso, após a reforma, 
muitos inquiridos pensam apoiar os filhos cuidando dos seus netos, de modo a libertarem-nos dos elevados custos das creches norte-americanas. Por conseguinte, é evidente que é o sentimento familiar que mais afasta os emigrantes da Graciosa. As outras razóes referidas relacionam-se, de uma forma geral, com o facto de a Graciosa não poder oferecer os mesmos bens e serviços que o país estrangeiro disponibiliza e que têm acesso, daí considerarem que um eventual regresso implicaria uma descida do seu nível de vida.

Para os poucos imigrantes que desejam o regresso permanente à Graciosa, cerca de $60 \%$ declararam que são as saudades da terra natal que constituem o principal motivo pelo retorno. Neste caso, encontramos casais que apesar de terem descendentes no país estrangeiro (filhos e/ou netos) náo desistem do sonho de voltar à terra que os "viu nascer". São emigrantes que nunca se adaptaram ao novo estilo de vida oferecido pelos EUA. Em segundo lugar, e com $30 \%$, surge um grupo de inquiridos que menciona que a Graciosa é melhor para descansar, oferecendo deste modo melhor qualidade de vida. Pretendem assim uma reforma tranquila, longe da agitação dos grandes centros urbanos. Desta forma, é evidente a relatividade do conceito de qualidade de vida.

\section{CONSIDERAÇÓES FINAIS}

Este trabalho abrangeu uma amostra que pretendeu ser representativa das comunidades emigrantes graciosenses nos estados norte-americanos da Califórnia e de Massachusetts. Observamos que no momento da chegada ao novo país, os indagados apresentaram sempre o mesmo perfil, contudo, o estado atlântico apresentou um número de emigrantes bastante superior. Além disso, notamos que ambas as comunidades desenvolveram relaçóes diferenciadas entre os próprios emigrantes e com a terra natal. Deste modo, como os emigrantes de Massachusetts encontram-se mais concentrados, revelam maior contacto entre eles e também com a sua terra natal. $\mathrm{Na}$ Califórnia, como os emigrantes se encontram mais dispersos no espaço não há uma tão grande afectividade entre eles e com a terra natal, até porque os inquiridos já não possuem relações familiares de grande proximidade com os actuais habitantes da Graciosa.

Contudo, é indiscutível que a grande maioria dos emigrantes atingiu o seu grande objectivo, isto é, melhorar o nível de vida da sua família.

Por fim, prevemos que à medida que as relaçóes familiares entre os residentes na ilha $\mathrm{e}$ os emigrantes se vão extinguindo, o contacto dos emigrantes e dos seus descendentes com a Graciosa poderá acabar por desaparecer.

\section{REFERÊNCIAS BIBLIOGRÁFICAS}

Espínola, P. 2008, A Emigração na ilha Graciosa, Dissertação de Mestrado em Geografia, área de especialização em Geografia Humana - Território e Desenvolvimento, FLUC, Coimbra.

Ferreira, A. 1987, A Ilha Graciosa, 2a Edição, Livros Horizonte, Lisboa.

Fortuna, M. 1986, “O impacto da emigração na economia açoriana”, Congresso das Comunidades Açorianas, n 2, Angra do Heroísmo pp. 413 - 432.

Instituto Nacional de Estatística, 1983, XII Recenseamento Geral da População: Resultados definitivos dos Açores 1981, INE, Lisboa. 